\title{
The Determination of Blood Histamine in Asthmatic Patients with a Simple and Sensitive Method
}

\author{
Hiroshi Izumi, Shinetsu Hoshi, ${ }^{*}$ Suetsuge Mue, ${ }^{*}$ \\ Tamotsu Takishima, ${ }^{*}$ Hiroyasu Sato and Tsuyoshi \\ AоKI \\ Department of Physiology, Tohoku University School of \\ Dentistry, and* the First Department of Internal Medicine, \\ Tohoku University School of Medicine, Sendai 980
}

\begin{abstract}
Izumi, H., Hoshi, S., Mue, S., Takishima, T., Sato, H. and Aoki, T. The Determination of Blood Histamine in Asthmatic Patients with a Simple and Sensitive Method. Tohoku J. exp. Med., 1984, 143 (1), 79-85— The histamine level of whole blood and plasma in asthmatic patients was estimated by means of a simple, sensitive and specific method, which was developed to measure low histamine levels. This method consists of the following procedures; the partial purification of histamine with a small $\mathrm{P}$-cellulose column ; its further purification with high performance liquid chromatography (HPLC); and fluorometric detection with precolumn o-phthaldehyde (OPT) reaction. The present assay could detect as little as $0.5 \mathrm{ng}$ of histamine concentration. Blood histamine levels in patient with asthmatic attack, $57 \pm 34 \mathrm{ng} / \mathrm{ml}$ (mean \pm S.D. $N=14$ ), were significantly different from those in symptom-free period, $37 \pm 15 \mathrm{ng} / \mathrm{ml}(N=15)$ as well as those in normal subjects, $36 \pm 17 \mathrm{ng} / \mathrm{ml}(N=12)$. However, there were no significant differences among plasma histamine levels in normal subjects, $1.6 \pm 1.7$ $\mathrm{ng} / \mathrm{ml}(N=12)$ and, in asthmatic patients during attacks, $1.6 \pm 1.8 \mathrm{ng} / \mathrm{ml}(N=14)$ and symptom-free periods, $1.6 \pm 1.7 \mathrm{ng} / \mathrm{ml}(N=15)$. These results indicate that plasma histamine concentration does not increase during asthmatic attacks, even though there was significant increase of blood histamine concentration.- histamine; HPLC; bronchial asthma
\end{abstract}

Histamime has been suggested to be one of the important chemical mediators for asthmatic attack, which is liberated from mast cells in the lung and triggers specific pathophysiological conditions of bronchial asthma. Recently, Adams and Lichtenstein (1979) indicated that histamine was involved in the early phase of bronchoconstriction of passively sensitized human lung after its release from mast cells by antigen challenge. However, there is some controversy as to whether or not the plasma level of histamine is actually increased in asthmatic patients (Beall 1963; Porter and Mitchell 1970, 1972; McFadden et al. 1980; Atkin et al. 1980). This seems to be in part due to the technical difficulties in plasma histamine measurement because of lack of sensitivity and specificity of

Received for publication, September 9, 1983. 
assay (Gleich and Hull 1980).

In this paper, a simple, sensitive and specific method of histamine determination, which combines small P-cellulose column for the partial purification of histamine from other interfering chemical substances, high performance liquid chromatography (HPLC)-system for its further purification, and fluorometric detection with precolumn o-phthaldehyde (OPT) reaction, has been developed. Using this method, histamine levels in venous blood and plasma from normal volunteers and asthmatic patients both during attacks and in symptom-free periods were determined.

\section{Materials and Methods}

\section{Subjects}

The subjects studied were 1) 12 healthy volunteers (9 men and 3 women), whose ages ranged from 21 to 36 years, having no history of atopic disease, and 2) asthmatic patients (6 men and 11 women), who were seen at the allergy clinic of Tohoku University Hospital, Sendai, and they were diagnosed as having intrinsic type asthma according to Rackeman's criteria.

\section{Determination of histamine concentration in blood and plasma}

The procedures are shown in Fig. 1. Blood was drawn from the antecubital vein into a heparinized disposable syringe. Plasma was obtained by centrifugation of aliquot of the

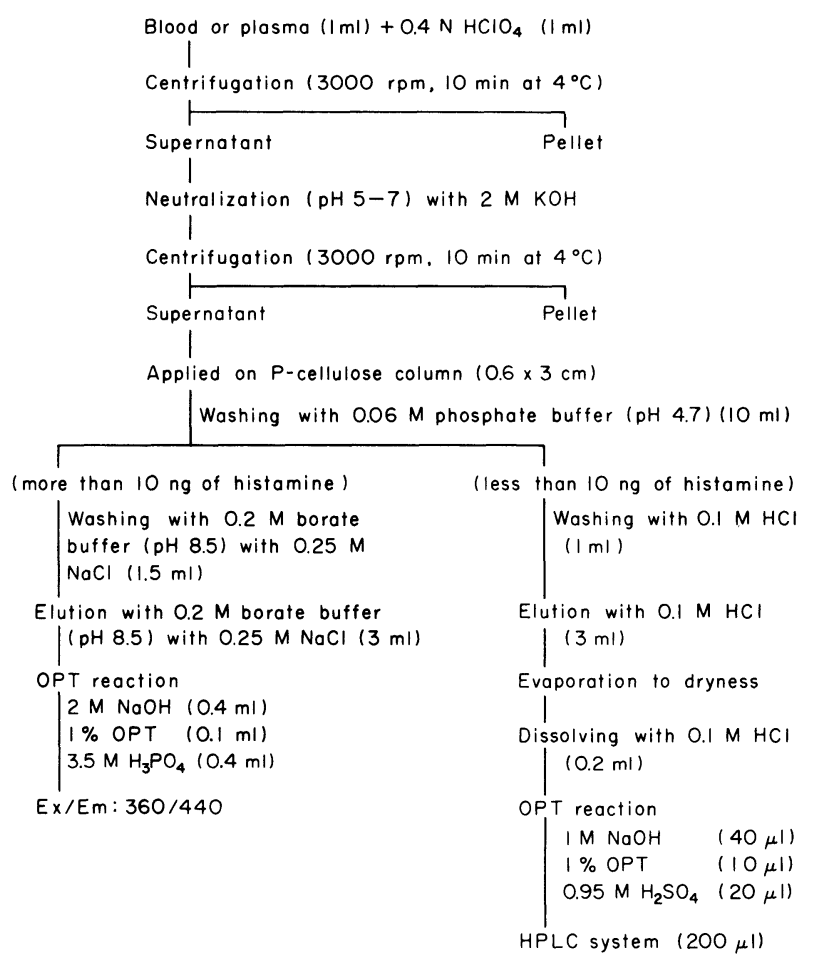

Fig. 1. Procedure of histamine determination in blood and plasma. 
blood sample at $3000 \mathrm{rpm}$ for $10 \mathrm{~min}$ at $4^{\circ} \mathrm{C}$. To each one $\mathrm{ml}$ of blood or plasma, an equal volume of $0.4 \mathrm{M} \mathrm{HClO}_{4}$ was added. After vigorously stirring, the mixture was centrifuged at $3000 \mathrm{rpm}$ for $10 \mathrm{~min}$. The supernatant was then stored in a glass tube at $-20^{\circ} \mathrm{C}$ until assay. Under these conditions of collection and storage, the histamine content remained stable for several months. The partial purification procedure of histamine was carried out by using P-cellulose which was reported by Endo (1981).

Measurement of blood histamine concentration (more than $10 \mathrm{ng}$ ). Histamine was eluted with $0.2 \mathrm{M}$ borate buffer ( $\mathrm{pH} 8.5$ ) containing $0.025 \mathrm{M} \mathrm{NaCl}$. The eluate was mixed wich $2 \mathrm{M} \mathrm{NaOH}(0.4 \mathrm{ml})$ and $1 \%$ OPT in methanol $(0.1 \mathrm{ml})$ for the OPT reaction. Four minutes later at room temperature, $0.4 \mathrm{ml}$ of $3.5 \mathrm{M} \mathrm{H}_{3} \mathrm{PO}_{4}$ was added to stop the reaction. The fluorescence was measured by a Jasco-FP-550 Spectrofluorometer (Japan Spectroscopic Co. Tokyo) at Ex. $360 \mathrm{~nm} / \mathrm{Em} .440 \mathrm{~nm}$.

Measurement of plasma histamine concentration (less than $10 \mathrm{ng}$ ). Histamine was eluted wich $3 \mathrm{ml}$ of $0.1 \mathrm{M} \mathrm{HCl}$. The eltuate was collected in a centrifuge tube, evaporated to dryness by a centrifugal evaporator, and dissolved in $0.2 \mathrm{ml}$ of $0.1 \mathrm{M} \mathrm{HCl}$. Then the solution was mixed wich $40 \mu \mathrm{l}$ of $1 \mathrm{M} \mathrm{NaOH}$ and $10 \mu \mathrm{l}$ of $1 \%$ OPT reaction. Four minutes later, $20 \mu \mathrm{l}$ of $0.95 \mathrm{M} \mathrm{H}_{2} \mathrm{SO}_{4}$ was added to stop the reaction. Aliquot $(200 \mu \mathrm{l})$ of the reaction mixture was injected into the HPLC-fluorescence analysis system, which consisted of a Model 204 Liquid Chromatograph with a 6000A Solvent Delivery System, a U6K Universal Injector, a Waters Radial Pack A column (Waters Associates Inc. Milford, MA, USA), and the Jasco-FP-550 Spectrofluorometer equipped with a flow-cell unit (FA-1030, cell volume; $15 \mu \mathrm{l})$. The mobile phase was a mixture of $0.5 \mathrm{M}$ phosphate buffer $(\mathrm{pH} 4.7)$ $(75 \mathrm{ml})$, triethylamine $(0.38 \mathrm{ml}), 0.2 \mathrm{M} \mathrm{HCl}(15 \mathrm{ml})$, and methanol $(90 \mathrm{ml})$. The flow rate was set at $1.0 \mathrm{ml} / \mathrm{min}$. The fluorescence intensity was monitored at Ex. $360 \mathrm{~nm} / \mathrm{Em}$. 440 nm.

\section{Materials}

Histamine $\cdot 2 \mathrm{HCl}$ and triethylamine were obtained from Wako Pure Chemicals, Osaka. OPT was purchased from Nakarai Chemicals, Tokyo. All other chemicals of reagent grade were obtained from general commercial sources.

\section{RESULTS}

Fig. 2 shows the HPLC chromatograms obtained after OPT reaction with various concentrations of histamine $(0-10 \mathrm{ng})$. Linear relationships between the fluorescence intensity and the amount of histamine concentration (0-10 ng) was definite (Fig. 3), indicating that as little as $0.5 \mathrm{ng}$ of histamine concentration could be detected. The recovery of histamine was checked by adding known amounts of histamine $(0-10 \mathrm{ng})$ to pooled plasma. The recoveries were $96.7 \%$. When the standard samples of various concentrations of histamine (10-100 ng) were added to $1 \mathrm{ml}$ of whole blood from a normal subject (Fig. 4), the linear relationship was also retained. The recovery of histamine in blood were $90.5 \%$. Chemical compounds such as spermine, spermidine, putrescine, agmatine, and cadaverine, which may be eluted from a P-cellulose column as reported by Endo (1981), were examined whether or not they would interfere the measurement of histamine concentration in the present method. Among them, only spermidine formed the fluorophore with OPT, but HPLC system could separate it from histamine. The retention times of histamine-OPT fluorophore and spermidine-OPT fluorophore were $4.8 \mathrm{~min}$ and $6 \mathrm{~min}$, respectively. 


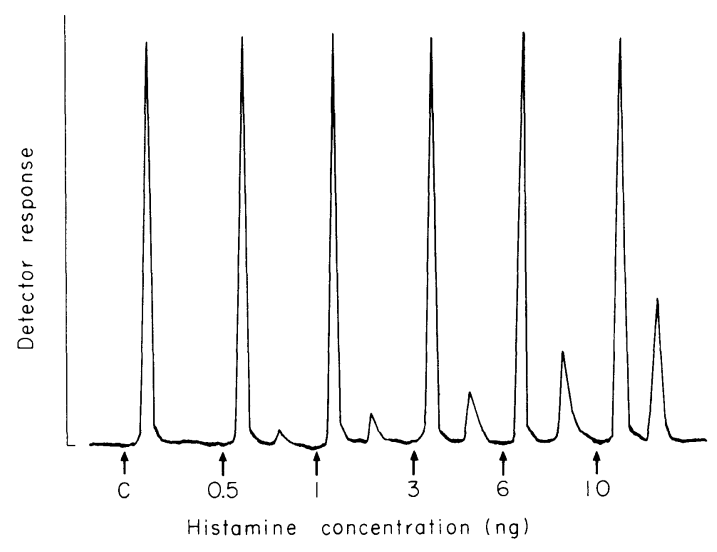

$\lcm{036}$ Time $(\mathrm{min})$

Fig. 2. HPLC chromatograms of standard histamine after OPT reaction. Various concentrations of histamine $(0-10 \mathrm{ng})$ dissolved in $0.4 \mathrm{~N} \mathrm{HClO}_{4}(2$ $\mathrm{ml}$ ) were injected to HPLC after the treatment with same procedure for the measurement of plasma histamine concentration.

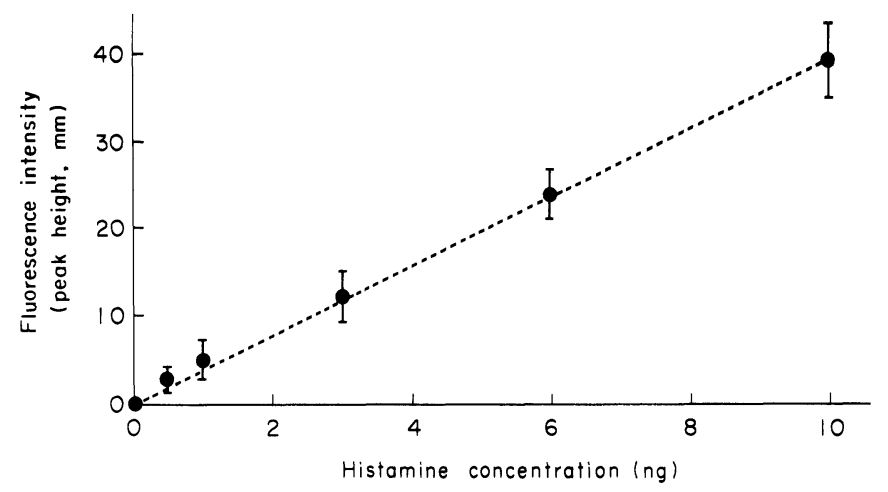

Fig. 3. The linear relationship between histamine concentration and fluoroscence intensity by HPLC. See detail in Fig. 1.

Blood and plasma histamine levels in normal subjects and asthmatic patients both during attacks and in symptom-free periods were shown in Table 1. The blood histamine levels of asthmatic patients during attacks, $57 \pm 34 \mathrm{ng} / \mathrm{ml}$ (mean \pm s.D., $N=14$ ), were significantly higher than both those of normal subjects, $36 \pm 17 \mathrm{ng} / \mathrm{ml}(N=12)$ and those of the same patients in symptom-free periods, $37 \pm 15 \mathrm{ng} / \mathrm{ml}(N=15)(p<0.5$ in Student's $t$-test). On the other hand, plasma histamine levels in asthmatic patients during attacks and symptom-free periods are $1.6 \pm 1.8 \mathrm{ng} / \mathrm{ml}(N=14)$ and $1.6 \pm 1.7 \mathrm{ng} / \mathrm{ml}(N=15)$, respectively, being almost similar to those of normal subjects, $1.6 \pm 1.7 \mathrm{ng} / \mathrm{ml}(N=12)$. 


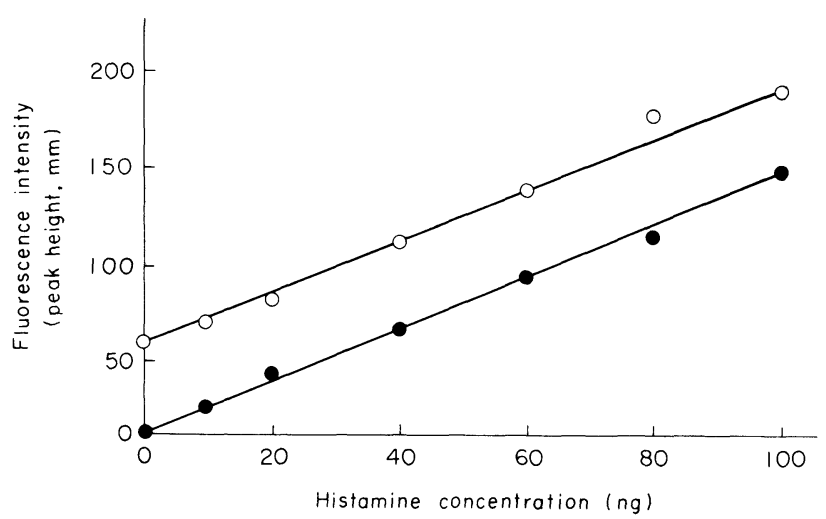

Fig. 4. Recovery of histamine standards $(0-100 \mathrm{ng})$ in whole blood. - - calibration curve for standard histamine; - $\mathrm{O}-$, calibration curve for standard histamine added to $1 \mathrm{ml}$ of whole blood from normal subject, which apparently contains $35 \mathrm{ng}$ of histamine.

\section{Discussion}

In the last decade, the enzymatic isotope procedure (Beaven et al. 1972) has been commonly used to measure low histamine levels in human plasma. This method needs to use a radioisotope and to purify a histamine- $\mathrm{N}$-methyltransferase enzyme, since it is based upon the conversion of histamine to ${ }^{14} \mathrm{C}$ methylhistamine by incubation with histamine-N-methyltransferase and S-adenosylmethionine- ${ }^{14} \mathrm{C}$-methyl. Previously, Tsuruta et al. (1978) applied HPLC for the measurement of plasma histamine levels after extraction of histamine with butanol and chroloform. When we measured histamine concentration using this method, we found that the extraction procedure gave variable and low recovery of histamine. The recovery of standard histamine added to the plasma and blood in the present method was $96.7 \%$ and $90.5 \%$, respectively. However, it should be taken into consideration that the quantitative relationship between the amount of P-cellulose in a column and that of blood or plasma applied on it is critical in the partial purification procedure with a P-cellulose column, because the capacity of P-cellulose varies with lot number of products even from the same company. Although Endo (1981) reported that spermine, spermidine, putrescine, agmatine and cadaverine were eluted from a P-cellulose column, these chemicals except spermidine in a dose up to $1 \mu \mathrm{g}$ showed no fluorescence in the OPT reaction. In addition, the HPLC system used in the present method could clearly separate spermidine from histamine. Thus, the procedure descrided in this paper has a number of advantages such as simplicity, specificity, and reproducibility, as well as sensitivity over many other methods previously reported (Beaven et al. 1972; Siraganian 1974 ; Tsuruta et al. 1978 ; Endo 1981).

The present assay of histamine which detects as little as $0.5 \mathrm{ng}$ of histamine concentration (Fig. 2) introduces new possibility in the investigation of the role of 
TABLE 1. Histamine levels in venous blood and plasma from normal subjects and patients with bronchial asthma

\begin{tabular}{|c|c|c|c|c|c|c|}
\hline & & & \multicolumn{4}{|c|}{ Histamine concentration $(\mathrm{ng} / \mathrm{ml})$} \\
\hline & & & \multicolumn{2}{|c|}{ Blood } & \multicolumn{2}{|c|}{ Plasma } \\
\hline \multicolumn{3}{|c|}{$\begin{array}{l}\text { Normal subjects } \\
\quad(N=12)\end{array}$} & \multicolumn{2}{|c|}{$\begin{array}{c}36 \pm 17 \text { (mean } \pm \text { s.D. }) \\
\text { (range, } 6-56)\end{array}$} & \multicolumn{2}{|c|}{$\begin{array}{c}1.6 \pm 1.7(\text { mean } \pm \text { s.D. }) \\
\text { (range, }<0.5-4.5)\end{array}$} \\
\hline \multicolumn{3}{|c|}{ Asthmatic patients } & \multirow{2}{*}{$\begin{array}{l}\text { During } \\
\text { attacks }\end{array}$} & \multirow{2}{*}{$\begin{array}{l}\text { In symptom } \\
\text { free periods }\end{array}$} & \multirow{2}{*}{$\begin{array}{l}\text { During } \\
\text { attacks }\end{array}$} & \multirow{2}{*}{$\begin{array}{l}\text { In symptom } \\
\text { free periods }\end{array}$} \\
\hline No & Age & Sex & & & & \\
\hline 1 & 52 & M & 40 & 25 & 1.5 & 0.5 \\
\hline 2 & 47 & M & 55 & 43 & $<0.5$ & 3.5 \\
\hline 3 & 28 & M & 101 & 47 & 0.5 & 0.5 \\
\hline 4 & 19 & M & 52 & 40 & $<0.5$ & 3.0 \\
\hline 5 & 56 & M & 35 & 21 & $<0.5$ & $<0.5$ \\
\hline 6 & 25 & M & 68 & NT & 4.0 & NT \\
\hline 7 & 60 & $\mathrm{~F}$ & 23 & 55 & $<0.5$ & $<0.5$ \\
\hline 8 & 61 & F & NT & 53 & 1.0 & 5.5 \\
\hline 9 & 39 & $\mathrm{~F}$ & 29 & NT & 5.5 & $\mathrm{NT}$ \\
\hline 10 & 59 & $\mathrm{~F}$ & 81 & 64 & 1.0 & 1.5 \\
\hline 11 & 40 & F & 136 & 39 & 4.0 & 1.5 \\
\hline 12 & 34 & F & 47 & 21 & 3.0 & 1.0 \\
\hline 13 & 50 & $\mathrm{~F}$ & 85 & 36 & 3.0 & 3.5 \\
\hline 14 & 31 & $\mathrm{~F}$ & 32 & 29 & 0.5 & $<0.5$ \\
\hline 15 & 32 & $\mathrm{~F}$ & 13 & 9 & 0.5 & $<0.5$ \\
\hline 16 & 53 & $\mathrm{~F}$ & NT & 37 & 0.5 & 2.5 \\
\hline 17 & 44 & $\mathrm{~F}$ & NT & 40 & NT & 0.5 \\
\hline \multicolumn{3}{|c|}{ Mean \pm S.D. } & $57 \pm 34^{*}$ & $37 \pm 15$ & $1.6 \pm 1.8$ & $1.6 \pm 1.7$ \\
\hline
\end{tabular}

M, male; F, female; NT, not tested. ${ }^{*} p<0.05$ compared with symptom free period and normal subjects (Student's $t$-test).

histamine in pathological conditions in man. The concentration of histamine in the plasma of 12 normal subjects determined by the present method varied from less than $0.5 \mathrm{ng} / \mathrm{ml}$ to $4.5 \mathrm{ng} / \mathrm{ml}(1.6 \pm 1.7 \mathrm{ng} / \mathrm{ml}$, mean \pm s.D. $)$, which indicates great fluctuation among normal individuals. This value was a little higher than those estimated by Beaven et al. (less than $0.5 \mathrm{ng} / \mathrm{ml}$ ) (1972) and Tsuruta et al. (0.61土 $0.16 \mathrm{ng} / \mathrm{ml}$ ) (1978). As shown in Table 1, blood histamine levels in asthmatic patients during attacks were significantly higher than those in symptom-free periods as well as those of normal subjects. In contrast, plasma hisamine levels in asthmatic patients during attacks were not different from those in symptom-free periods as well as those in normal subjects, despite the usage of the present sensitive and reliable assay of histamine. Thus, it seems clear that histamine increase in blood is not due to the increase of histamine in plasma. It may be also 
possible that failure to find the elevation of plasma histamine level is in part due to the time at which we collected the blood, because the time of blood collection is very critical to assay histamine in antigen provocation test. Furthermore, it is well known that histamine is rapidly metabolized when administered intravenously (Waalkes et al. 1957). So far, we could not find any explanations for an increase in whole blood histamine levels in asthmatic attacks.

\section{References}

1) Adams, G.K. \& Lichtenstein, L.M. (1979) In vitro studies of antigen-induced bronchospasm: Effect of antihistamine and SRS-A antagonist on response of sensitized guinea pig and human airways to antigen. J. Immunol., 122, 555-562.

2) Atkins, P.C., Rosenblum, F., Dunsky, E.H., Coffey, R. \& Zweiman, B. (1980) Comparison of plasma histamine and cyclic nucleoyides after antigen and methacholine inhalation in man. J. Allergy, 66, 478-485.

3) Beall, G.N. (1963) Plasma histamine concentrations in allergic diseases. J. Allergy, 34, 8-15.

4) Beaven, M.A., Jacobson, S. \& Horakova, Z. (1972) Modification of the enzymatic isotopic assay of histamine and its application to measurement of histamine in tissues, serum and urine. Clin. chim. Acta, 37, 91-103.

5) Endo, Y. (1981) Simple method for the simultaneous determination of histamine, polyamines and histone H1. J. Chromatogr., 205, 155-164.

6) Gleich, G.H. \& Hull, W.M. (1980) Measurement of histamine: A quality control study. J. Allergy clin. Immunol., 66, 295-298.

7) McFadden. E.R., Jr., Soter, N.A. \& Ingram, R.H., Jr. (1980) Magnitude and site of airway response to exercise in asthmatics in relation to arterial histamine levels. $J$. Allergy, 66, 472-477.

8) Porter, J.F. \& Mitchell, R.G. (1970) The Distribution of histamine in the blood of healthy and asthmatic children. Clin. Sci., 38, 135-143.

9) Porter, J.F. \& Mitchell, R.G. (1972) Distribution of histamine in human blood. Physiol. Rev., 52, 361-381.

10) Siraganian, R.P. (1974) An automated continuous-flow system for the extraction and fluoromethic analysis of histamine. Analyt. Biochem., 57, 383-394.

11) Tsuruta, Y., Kohashi, K. \& Okura, Y. (1978) Determination of histamine in plasma by high-speed liquid chromatography. J. Chromatogr., 146, 490-493.

12) Waalkes, T.P., Weissbach, H. Bozicevich, J. \& Udenfriend, S. (1957) Serotonin and histamine release during anaphylaxis in the rabbit. J. clin. Invest., 36, 1115-1120. 